\title{
A proposta de um novo itinerário de leitura para as obras prudentianas
}

\author{
A proposal for a new reading itinerary concerning the works of \\ Aurelius Prudentius
}

GONÇALVES, A. T. M. A arte poética a serviço do proselitismo cristão: relendo os poemas de Aurélio Prudêncio Clemente

(séculos IV/V). Jundiaí: Paco, 2020. 276 p.

\section{Rodrigo Santos Monteiro Oliveira*}

Recebido em: 25/07/2021

Aprovado em: 28/10/2021

ensar o proselitismo cristão é ponderar a existência de dois personagens essenciais: o que deseja convencer e o alvo da persuasão almejada. Tal ação abrange vastíssimas possibilidades de condutas com o intuito de persuadir alguém a respeito de alguma(s) crença(s) religiosa(s), "decorrentes do direito mais vasto de manifestar as suas convicções religiosas, tentando convencer os outros da verdade e benefícios das respectivas convicções" (GUERREIRO, 2013, p. 3-4). E é isto que Prudêncio almeja realizar ao pensar a escrita e a propagação de seus poemas em um ambiente ainda dividido entre costumes e crenças religiosas diversas; é a disputa pelos espaços físicos e mentais que estão em jogo quando o autor se propõe a convencer seus contemporâneos à conversão e/ou aos "verdadeiros" cânones da fé cristã.

A partir das obras prudentianas, a Profa. Dra. Ana Teresa Marques Gonçalves propôs o desenvolvimento de uma nova possibilidade ordenadora para uma sequência de leitura apropriada à análise do conteúdo e dos objetivos do autor. O trabalho de pesquisa que originou o livro A arte poética a serviço do proselitismo cristão foi desenvolvido para a defesa em banca de promoção ao cargo de professora titular de História Antiga da Faculdade de História (UFG), no lugar de um memorial acadêmico e dos destaques biográficos da produção pela professora realizada. Tal preferência já nos demonstra o esforço contínuo

* Doutor pelo Programa de Pós-Graduação em História da Universidade Federal de Goiás (UFG). Mestre e graduado em História pela UFG. 
ao qual a autora se submeteu ao longo de toda a sua carreira acadêmica; da graduação na UFRJ para a docência na UFG (iniciada em 1995), com passagens pela USP e pela UFOP, Ana Teresa Marques Gonçalves desenvolveu vasta produção bibliográfica a respeito de temas distintos daquilo que convencionamos denominar como Antiguidade Clássica. Hoje, a pesquisadora é professora associada de História Antiga e Medieval na UFG, sendo bolsista produtividade do CNPq.

Além da aferição dos conteúdos dispostos por Prudêncio ao longo de suas várias obras produzidas entre os séculos IV e V, a docente e pesquisadora propõe uma organização para a leitura destas, estabelecendo qual deve ser lida primeiro e qual por último. Tal sequência não se produz por preferências pessoais ou pela aleatoriedade, mas por uma possível melhor apreensão do que era proposto pelo autor. É uma organização que permite o leitor "viajar" do geral para o particular (GONÇALVES, 2020, p. 248), daquilo que foi promovido por Prudêncio como uma resposta direta ao seu contexto e aos eventos concretos à discussão do que a alma humana necessita para se aproximar da verdade em Deus.

Na vastidão das obras, algumas ideias são recorrentes, sendo elas: a construção da unicidade do pensamento e da expressão do cristianismo e combate aos discursos heréticos; defesa do livre arbítrio humano e de sua aproximação às virtudes bíblicas; construção de ambientes que facilitassem o proselitismo para gerar conversão, adesão e confirmação à fé; defesa do monoteísmo.

Em uma divisão de cinco capítulos (fora a introdução e as considerações finais), temos o seguinte itinerário: é apresentado, no Capítulo 1, críticas contra Símaco e à reposição de estátuas pagãs em locais públicos, o que possibilita a compreensão do contexto de produção do autor e sua defesa contra os antigos costumes e crenças de Roma; no Capítulo 2, são apresentados dois poemas, Apotheosis e Hamartigenia, pela defesa da unidade cristã e condenação dos pensamentos desviantes; a partir das obras Cathemerinon e Dittochaeon é realizada, no Capítulo 3, a apresentação de ferramentas que auxiliariam os convertidos a se manterem firmes, e aos gentios de optarem pela conversão; nos últimos dois Capítulos, 4 e 5, são apresentadas as obras Peristephanon e Psychomachia que ajeitam, respectivamente, a formação de novos heróis para os cristãos, substituindo os pagãos, e o embate entre as virtudes e os vícios dos quais os convertidos deveriam se aproximar e se afastar.

Toda a apresentação realizada e a nova proposta de leitura são embasadas em conceitos-base que introduzem o livro resenhado na gama de outras obras que almejam discutir temáticas acerca dos cristianismos (CHEVITARESE, 2016); apontamos, como exemplo, a periodização em Antiguidade Tardia (FRIGHETTO, 2012) estabelecida para a 
demarcação contextual da obra, os conceitos de memória, imaginário (e suas intrínsecas relações), já ligados à linha de pesquisa da própria pesquisadora como componente do Programa de Pós-Graduação em História da UFG, e retórica.

São inúmeros os autores que, ao longo da Antiguidade Tardia e do Medievo, citaram Prudêncio (Sidônio Apolinário, Epistola, II. 9; Verecundo, De Satisfactione Poenitentiae; ${ }^{7}$ Julião de Toledo, Glossamata; entre outros), informação que confirma de forma ainda mais evidente a importância de estudar esse autor para os que desejam entender a formação do imaginário romano-cristão na passagem dos séculos IV e V. O intenso diálogo com a tradição pagã demonstra o esforço discursivo de Prudêncio em se aproximar de um público ainda não convertido; como Paulo, que defendeu a abordagem cristã junto aos gentios (Paulo, Epistula ad Galatas, II, 11-14), Prudêncio se lançou ao desafio de conquistar "novas almas para Cristo".

Assim como a karthásis é o fim de uma peça de tragédia, para Georges Balandier (1983) o fim do drama do discurso é a comoção ou o convencimento, estratégias retóricas muito bem aproveitadas nos embates entre diferentes atores. $O$ discurso não é um espaço de alucinação individual em que o autor se desprende completamente daquilo que o formou, mas um sistema bem estruturado que determina certo imaginário social, pois estabelece, em maior ou menor medida, poder e controle. O imaginário se associa de forma plena ao real, ou à possibilidade do que isto seria, pois se baseia na realidade para transformá-la em algo que é necessário interpretar.

Dessa maneira, buscamos compreender o discurso para além da organização enunciativa. A comunicação, proposta de qualquer discurso analisado, não está "inteiramente no [próprio] discurso, nem mesmo nas relações" (BOURDIEU, 2003, p. 162). Pois, "[...] uma verdadeira ciência do discurso deve buscar neste, mas também fora dele, nas condições sociais de produção e de reprodução dos produtores e receptores e da relação entre eles" (BOURDIEU, 2003, p. 162).

É pela comunicação discursiva constante com vasto público de convertidos e gentios que Prudêncio demonstra estar bem familiarizado com a formação clássica, e o que faz do esforço de análise das obras destacadas, assim como a realizada na obra sobre a qual resenhamos, uma difícil tarefa; é preciso ter contato com o referencial clássico a fim de compreender os métodos comparativos utilizados pelo autor, aproximando-nos das possíveis chaves interpretativas de seus contemporâneos. Um trabalho de grande esforço em ler uma obra cristã do século IV que possui como referência autores, como Horácio,

${ }^{1}$ Verecundo, bispo de Junca (África), utilizou Prudêncio em seus versos De Satisfactione Poenitentiae, com 242 hexâmetros (RODRIGUEZ, 1990, p. 56). 
Ovídio e Virgílio. Para se opor é preciso conhecer, e tanto Prudêncio quanto Gonçalves demonstram tal tirocínio.

O proselitismo prudentiano não destoa do esforço de muitos outros ao longo do mesmo período, ao mesmo tempo em que suas obras proporcionam uma nova perspectiva a fim de entender as mudanças religiosas e ordenações sociais correlacionadas. O livro A arte poética a serviço do proselitismo cristão, de Ana Teresa Marques Gonçalves, nos aproxima de fontes documentais ainda pouco analisadas pela historiografia brasileira e, a partir da contraposição com outras tantas abordagens internacionais, demonstra sua excepcionalidade.

Se Prudêncio não foi um homem cheio de posses materiais, capaz de ofertar aos mais pobres sua grande riqueza, ofereceu com seus versos o conhecimento preciso para aproximar os desvirtuados do bom caminho (Prudêncio, Epilogus, 1-34). Aprender é preciso aos gentios e cristãos nos tempos de Prudêncio; e aos que estão interessados nestas lições realizadas, o itinerário de leitura indicado no livro que resenhamos é, sem dúvida, uma ótima proposta de aprendizado.

\section{Referências}

BALANDIER, G. O poder em cena. Brasília: Editora da UnB, 1983.

BíBLIA SAGRADA. São Paulo: Vida, 2003.

BOURDIEU, P. Economia das trocas linguísticas. In: ORTIZ, R. (org.). Bourdieu: sociologia. São Paulo: Ática, 2003, p. 156-183.

CHEVITARESE, A. L. Cristianismos: questões e debates metodológicos. Rio de Janeiro: Kliné, 2016.

FRIGHETTO, R. Antiguidade Tardia: Roma e as monarquias romano-bárbaras numa época de transformações (séculos II-VIII). Curitiba: Juruá, 2012.

GUERREIRO, S. As fronteiras da tolerância: liberdade religiosa e proselitismo na Convenção Europeia dos Direitos do Homem. Lisboa: Almedina, 2013.

MELLADO RODRIGUEZ, J. Léxico de los Concílios Visigóticos de Toledo. Cordoba: Servicio de Publicaciones de la Universidad de Cordoba, 1990.

PRUDÊNCIO. Obras completas. Tradução de Alfonso Ortega e Isidoro Rodrigues. Madrid: BAC, 1981.

SIDOINE APOLLINAIRE. Epistle: livres I-V. Edition, traduction e commentaires par A. Loyen. Paris: Les Belles Lettres, 2003b. v. 2. 